\title{
Schon Typ-2-Diabetes in der Familienanamnese ist ungünstig
}

Fragestellung: Gibt es einen Unterschied hinsichtlich der Wirksamkeit körperlicher Bewegung bei Personen mit und ohne Familienanamnese mit Diabetes?

Hintergrund: Wir wissen, dass Menschen mit Diabetes mellitus oft einen inaktiveren Lebensstil führen als Stoffwechselgesunde. Dabei gibt es eine Kontroverse, inwieweit das die Folge oder die Ursache für den Diabetes ist. Studien haben gezeigt, dass Diabetiker mehr Aufwand betreiben müssen, um das gleiche Level an körperlicher Aktivität zu erreichen, da sie einen physiologischen Nachteil haben. Dabei ist bisher unbekannt, inwieweit dieser physiologische Nachteil vererbt wird oder durch Insulinresistenz, viszerales Fett und Leberfett erworben ist. Weiterhin ist unbekannt, ob es Unterschiede zwischen gesunden Menschen mit und ohne Familienanamnese von Diabetes mellitus gibt. Diese Fragestellung ist in der vorliegenden Studie untersucht worden.

Patienten und Methoden: Die Studiengruppe um Ekman et al. vom Uniklinikum in Malmö, Schweden, untersuchten 16 Männer mit einer positiven Diabetesfamilienanamnese und 19 Männer ohne diese Ana-

Originalie

Ekman C, Elgzyri T, Ström K et al. Less pronounced response to exercise in healthy relatives to type 2 diabetics compared to controls. J Appl Physiol (1985) 2015;119(9):953-60 mnese, die ihrerseits aber alle keinen Diabetes hatten. Die Männer waren sich hinsichtlich Alter, $\mathrm{VO}_{2} \max$ und Body Mass Index ähnlich. Alle durchliefen eine Intervention zur Steigerung körperlicher Aktivität über 7
Wer den Diabetes Typ 2 in die Wiege gelegt bekommt, muss sich vermutlich mehr abstrampeln, um ihn nicht zu bekommen, als Menschen ohne diese Veranlagung, auch wenn er sonst gesund ist.

Monate und nahmen dabei im Schnitt an 39 Trainingssessions teil. Vor und nach der Intervention wurden die Teilnehmer körperlich untersucht, ein oraler Glukosetoleranztest wurde durchgeführt und Muskelbiopsien für Expressionsanalysen wurden gesammelt.

Ergebnisse: Beim Vergleich der Fitness stellte sich heraus, dass mithilfe der Intervention der $\mathrm{VO}_{2} \mathrm{max} / \mathrm{kg}$ um $14 \%$ zugenommen hat und die Teilnehmer im Schnitt 1,2 kg Gewicht abnahmen (3 $\mathrm{cm}$ Taillenumfang). Die Gruppe mit positiver Familienanamnese verbrauchte in der Trainingssession $61 \%$ mehr Energie im Vergleich zur Gruppe ohne. Interessanterweise hatte dieser gesteigerte Energieverbrauch keinen stärkeren Effekt auf die Veränderung anthropometrischer oder metabolischer Parameter. Bei der Expressionsanalyse wurden in der Gruppe ohne positive Familienanamnese Gene mit stärkerer Expression gefunden, die in Stoffwechselprozesse, oxidative Phosphorylierung und Zellatmungsprozesse involviert waren.

Schlussfolgerungen: Bei gesunden Menschen reagieren diejenigen mit einer Diabetesfamilienanamnese auf körperliche Aktivität anders als Gesunde ohne diese Familienanamnese. Die Autoren vermuten, dass die Familienanamnese die muskuläre Adaptation zu Sport und Bewegung limitiert und damit einen substanziellen Beitrag zum Diabetesrisiko leistet.

\section{- Kommentar von Prof. Dr. med. Peter Schwarz}

\section{Wer es "in den Genen" hat, muss sich noch mehr anstrengen}

Im Vergleich zur Studie von Huebschmann AG et al. BMJ Open Diabetes Research and Care 2015 hier im Heft gehen die schwedischen Forscher dieser Studie hier mehr in die Tiefe, um die Pathophysiologie hinter dem unterschiedlichen Effekt körperlicher Aktivität bei Diabetes und das Ansprechen von Diabetikern auf körperliche Aktivität zu verstehen. Zwar wurden hier gesunde Personen, die insulinsensitiv waren, untersucht, die sich nur eine differierende Familienanamnese hatten. Das überzeugendste Argument der Studie ist aber, dass die Gene, die mit diabetespräventiven Stoffwechselprozessen zu tun haben, beim gleichen Sportstimulus bei den Probanden ohne Familienanamnese viel stärker exprimiert wurden. Das ist ein klarer Vorteil für sie und ein klarer Hinweis auf ein reduziertes Diabetesrisiko. Eine Familienanamnese scheint auch bei (noch) Gesunden physiologische Stoffwechselpro- zesse negativ zu beeinflussen. Eigentlich ist uns das bekannt, die Relevanz auf physiologischer Ebene durch die Familienanamnese aber eher nicht.

Was können wir daraus ableiten? Vermutlich müssen Personen mit einer für Diabetes positiven Familienanamnese eher oder auch intensiver Sport treiben oder auch umso intensiver die Alltagsaktivität steigern, um den genetischen Nachteil zu kompensieren. Aber trotz einer positiven Familienanamnese ist der Diabetes keine Unausweichlichkeit. Die Quintessenz ist, dass Maßnahmen zur Diabetesprävention bei diesen Menschen besonders hohe Priorität haben sollte.

Prof. Dr. med. Peter Schwarz, MBA - Department of Medicine III, Prevention and Care of Diabetes, University of Dresden 